\title{
Low cost abiraterone
}

\author{
Diego Martin Barreiro, Francisco Castro
}

Instituto De Investigaciones Medicas Alfredo Lanari, University of Buenos Aires, Argentina

Contemp Oncol (Pozn) 2015; 19 (4): 420-421 DOI: $10.5114 /$ wo.2015.56661

Abiraterone is approved in combination with prednisone and a luteinizing hormone-releasing hormone (LHRH) analogue for castration-resistant prostate cancer (CPRC) patients progressing in the form of previa [1] or after treatment with docetaxel [2].

CPRC patients treated with abiraterone should take four tablets on an empty stomach one hour before breakfast, $10 \mathrm{mg}$ of prednisone, and continued treatment with analogue LHRH [3].

It is an effective drug but at a cost of $€ 36,693$ per patient per year [4]. In addition, the LHRH analogue costs from $€ 972$ to $€ 1788$ per patient per year [5] (€81-€149 per month depending on the European country).

Is it necessary to maintain this very expensive therapeutic scheme? Can we obtain the same results at a lower cost?

Theoretically abiraterone treatment can be nearly $80 \%$ cheaper with the same therapeutic results. This can be achieved with two modifications to current treatment:

\section{1) Suppression of the LHRH analogue}

It has been shown that the reboot in the production of testosterone by the testis after suspending the hormonal blockade is dependent on the duration of blockade [6].

After a year of hormonal blockade, in order to suspend it 73 to $100 \%$ of the patients recovered normal levels of testosterone within six months [7].

However, after three years of hormonal blockade only 0 to $18 \%$ of patients recovered the levels of testosterone at six months [8].

Regardless of the low production of testosterone in patients blocked for years, abiraterone suppresses the production of testosterone by the testis due to the fact that it blocks the synthesis of testosterone.

There are two phase II studies currently evaluating the use of single abiraterone; one is still recruiting patients, and the other, which will present its results in the year 2016 [10], published a small retrospective series of patients with the use of abiraterone without LHRH analogue in which all patients maintained values of testosterone in castration range [11].

So in patients with CPRC after several years of hormonal blockade it could be possible to discontinue the use of the LHRH analogue.

\section{2) Reduce the dose of abiraterone to $250 \mathrm{mg}$ per day}

If, according to the datasheet of the FDA [12], a meal of $300 \mathrm{Kcal}$ and $7 \%$ fat increases by about five times $(5 \times$ AUC and $\left.C_{\max } 7 \times\right)$ the bioavailability, then one tablet $(250 \mathrm{mg}$ ) taken together with a standardised light breakfast - less than $300 \mathrm{Kcal}$ and $7 \%$ fat - should produce abiraterone levels similar to those obtained with $1000 \mathrm{mg}$ /day on an empty stomach [4].

According to our calculations, this is done by taking the abiraterone pill with a 150-cc glass of whole milk.

Thus, a container of abiraterone would serve for four months of treatment and is not continuous with the LHRH analogue, with a consequent reduction in medical costs of treatment of the CPRC in comparison with other treatment alternatives, would be the most profitable from the point of view of cost benefit. It remains to wait for the results of prospective studies to endorse this dosage of abiraterone.

\section{References}

1. Ryan C, MSmith M, Bono J, et al. Abiraterone in metastatic prostate cancer without previous chemotherapy. N Engl J Med 2013; 368: 138-14.

2. de Bono JS, Logothetis CJ, Molina A, et al. Abiraterone and increased survival in metastatic prostate cancer. N Engl J Med 2011; 364: 1995-2005.

3. Heidenreich A, Bastian PJ, Bellmunt J, et al. EAU guidelines on prostate cancer. Part II: Treatment of advanced, relapsing, and castration-resistant prostate cancer. Eur Urol 2014; 65: 467-79.

4. Moreno Gómez Á, Abajo Del Álamo C, Catalá Pindado MÁ, Godoy Díez M. Some questions about abiraterone, breakfast and public funding. Farm Hosp 2015; 39: 120-121.

5. Wex J, Sidhu M, Odeyemi I, Abou-Setta AM, Retsa P, Tombal B. Leuprolide acetate 1-, 3- and 6-monthly depot formulations in androgen deprivation therapy for prostate cancer in nine European countries: evidence review and economic evaluation. Clinicoecon Outcomes Res. 2013 Jun 24;5:257-69.

6. Bong GW, Clarke HS Jr, Hancock WC, Keane TE. Serum testosterone recovery after cessation of long-term luteinizing hormone-releasing hormone agonist in patients with prostate cancer. Urology 2008; 71: 1177-80.

7. Nejat RJ, Rashid HH, Bagiella E, Katz AE, Benson MC. A prospective analysis of time to normalization of serum testosterone after withdrawal of androgen deprivation therapy. J Urol 2000; 164: 1891-4.

8. Kaku H, Saika T, Tsushima T, Ebara S, Senoh T, Yamato T, Nasu Y, Kumon $\mathrm{H}$. Time course of serum testosterone and luteinizing hormone levels after cessation of long-term luteinizing hormone-releasing hormone agonist treatment in patients with prostate cancer. Prostate 2006; 66: 439-44. 
9. A Phase 2, Randomized, 3-arm Study of Abiraterone Acetate Alone, Abiraterone Acetate Plus Degarelix, a GnRH Antagonist, and Degarelix Alone for Patients With Prostate Cancer With a Rising PSA or a Rising PSA and Nodal Disease Following Definitive Radical Prostatectomy. Available at: http://clinicaltrials.gov/ct2/ show/NCT01751451

10. Trial of Abiraterone Acetate Plus LHRH-therapy Versus Abiraterone Acetate Sparing LHRH-therapy in Patients With Progressive Chemotherapy-naïve Castration-resistant Prostate Cancer (SPARE) ClinicalTrials.gov Identifier: NCT02077634.

11. Barreiro DM, Castro Montiel F, Parise ML, et al. Abiraterona Sola. Rev Arg de Urol 2015; 80 (2) 2015 (in press).

12. FDA AUC US Food and Drug Administration: FDA labeling information: ZYTIGA. available at: http://www.accessdata.fda.gov/drugsatfda_docs/label/2011/202379lbl.pdf.

\section{Address for correspondence}

\section{Diego Martin Barreiro}

Instituto De Investigaciones Medicas Alfredo Lanari

University of Buenos Aires,

Av Combatientes De Malvinas 3159

C1427ARN Ciudad De Buenos Aires, Argentina

e-mail: DIEGOMARTINBARREIRO@hotmail.com

Submitted: 21.08 .2014

Accepted: $\quad 9.10 .2015$ 